\title{
Efficacy comparison of duloxetine and SSRIs at doses approved in Japan
}

\author{
This article was published in the following Dove Press journal: \\ Neuropsychiatric Disease and Treatment \\ 12 January 2015 \\ Number of times this article has been viewed
}

\section{Eiji Harada' \\ Alexander Schacht ${ }^{2}$ \\ Tsukasa Koyama ${ }^{3}$ \\ Lauren B Marangell ${ }^{4,5}$ \\ Toshinaga Tsuji ${ }^{6}$ \\ Rodrigo Escobar ${ }^{4}$}

'Medical Science, Eli Lilly Japan K.K, Kobe, Japan; ${ }^{2}$ Global Statistical Sciences, Eli Lilly and Company, Bad Homburg, Germany; ${ }^{3}$ Clinical Research Center, Ohyachi Hospital, Sapporo, Japan; ${ }^{4}$ Eli Lilly and Company, Indianapolis, IN, ${ }^{5}$ The University of Texas Health Science Center, Houston, TX, USA; ${ }^{6}$ Medical Affairs, Shionogi \& Co Ltd, Osaka, Japan
Correspondence: Eiji Harada Medical Science, Eli Lilly Japan K.K, 7-I-5, Isogamidori, Chuo-ku, Kobe 65I-0086, Japan

Tel +81782424064

Fax +8I 782429526

Email harada_eiji@lilly.com
Background: Approved doses of antidepressants in Japan are usually lower than those in the USA and European Union, but to date meta-analyses comparing antidepressants have all used the higher doses approved in the USA and European Union and often have used indirect comparisons. The purpose of this study was to conduct an integrated database analysis of patient level data to compare the effects of duloxetine with those of selective serotonin reuptake inhibitors (SSRIs) at the doses approved in Japan.

Methods: Pooled data were analyzed from four randomized, double-blind, placebo-controlled studies that compared duloxetine at the dose range approved in Japan (40-60 mg/day) with other SSRIs (paroxetine $20 \mathrm{mg}$ /day or escitalopram $10 \mathrm{mg}$ /day) and placebo in patients with major depressive disorder. In total, 1,694 patients were included in the analysis (duloxetine, $\mathrm{n}=688$; selective serotonin reuptake inhibitors, $\mathrm{n}=690$; placebo, $\mathrm{n}=316$ ). The primary outcome measure was the mean change from baseline at week 8 in 17-item Hamilton Rating Scale for Depression $\left(\mathrm{HAMD}_{17}\right)$ total and subscale scores.

Results: Duloxetine and both selective serotonin reuptake inhibitors were superior to placebo in $\mathrm{HAMD}_{17}$ total score at week 8 in both the all-randomized group and the more severe subgroup ( $\mathrm{HAMD}_{17}$ total scores $\geq 19$ ). Duloxetine was superior to SSRIs in improving the $\mathrm{HAMD}_{17}$ Retardation subscale score (least squares mean difference [ $95 \%$ confidence interval]): all-randomized group, $-0.33[-0.60,-0.07], P=0.015$; severe subgroup, $-0.45[-0.83,-0.07]$, $P=0.020)$.

Conclusion: Within the dose range approved in Japan for patients with major depressive disorder, duloxetine and selective serotonin reuptake inhibitors demonstrated comparable overall efficacy, with a possible advantage for duloxetine in improving loss of energy and interest. To the best of our knowledge, this analysis is unique not only in evaluating dosages specific to Japan, but also in using individual patient data and the same endpoint across studies to allow for strictly direct head-to-head data comparisons as opposed to pooling direct and indirect comparisons.

Keywords: duloxetine, selective serotonin reuptake inhibitors, Japan, approved dosage, metaanalysis, major depressive disorder

\section{Introduction}

Antidepressants are the mainstay of treatment for adult major depressive disorder (MDD). Selective serotonin reuptake inhibitors (SSRIs), serotonin and norepinephrine reuptake inhibitors, and noradrenergic and specific serotonergic antidepressants are categorized as first-line treatments in many countries, including Japan. ${ }^{1,2}$ Thus, health care providers have the opportunity to choose an antidepressant from a variety of firstline treatment options. To select the most appropriate treatment for each patient, it is important for clinicians to be aware of the differences in efficacy between comparable antidepressants at the doses approved in their countries. 
One long-standing approach to comparing efficacy has been meta-analysis of several randomized controlled trials that compare widely used treatments. ${ }^{3-10}$ However, results have been inconsistent, perhaps partly due to the use of different methodologies. Recent meta-analyses have used mixed treatment comparisons in which both direct and indirect comparisons were used. ${ }^{11,12}$

Duloxetine, a second-generation norepinephrine reuptake inhibitor that has demonstrated efficacy, safety, and tolerability in patients with MDD, ${ }^{13-16}$ has been the subject of several recent mixed treatment comparisons. A recent analysis by Cipriani et al ${ }^{12}$ compared the effects of 12 new-generation antidepressants in adults with MDD, and Gartlehner et al ${ }^{11}$ conducted an analysis of 234 studies that included placebo as a comparator. However, these results are not applicable to clinical practice in Japan, because they included data from patients taking duloxetine up to $120 \mathrm{mg} /$ day, which is twice the maximum dosage ( $\leq 60 \mathrm{mg} /$ day) approved in Japan. Another drawback was the inclusion of patients who took antidepressants not approved or not even available for use in Japan. Therefore, it is uncertain whether these results can be applied to daily clinical practice in countries (eg, Japan) where the approved dosage for duloxetine is $40-60 \mathrm{mg} /$ day and SSRIs are limited to four compounds, ie, paroxetine, sertraline, escitalopram, and fluvoxamine. To the best of our knowledge, there are no meta-analyses that compare the efficacy of duloxetine $\leq 60 \mathrm{mg}$ /day with these SSRIs. The primary purpose of the current study was to provide clinicians with efficacy results that would allow a comparison of duloxetine $\leq 60 \mathrm{mg}$ /day with four approved SSRIs in Japan.

\section{Materials and methods}

\section{Study selection and data collection}

The Eli Lilly clinical trial database contains all clinical trials of duloxetine for patients with MDD that were conducted by Eli Lilly or its partners outside of Japan. We reviewed this database and selected randomized controlled trials that included duloxetine and SSRI for the acute treatment of MDD. For the SSRI selection, four SSRIs that were approved in Japan for the treatment of MDD (eg, paroxetine, sertraline, escitalopram, and fluvoxamine as of July 2014) were included. As a result, a total of four studies (three studies on duloxetine 40 or $80 \mathrm{mg}$ / day versus paroxetine $20 \mathrm{mg}$ /day and one study on duloxetine $60 \mathrm{mg} /$ day versus escitalopram $10 \mathrm{mg} /$ day) were selected (Table 1). As a next step, patients who received more than the approved daily dose ranges in Japan (duloxetine $80 \mathrm{mg} /$ day) were excluded from the analysis. No studies meeting the criterion for comparison were excluded.
Table I Studies included in pooled analysis

\begin{tabular}{|c|c|c|c|c|}
\hline Studies & $\begin{array}{l}\text { Inclusion } \\
\text { criteria }\end{array}$ & $\begin{array}{l}\text { Duration } \\
\text { (weeks) }\end{array}$ & Treatment & $\mathbf{n}$ \\
\hline HMAT A & $\begin{array}{l}\text { MDD } \\
\text { HAMD } \geq 15 \\
\text { CGI-S } \geq 4\end{array}$ & 8 & $\begin{array}{l}\mathrm{DLX} 40 \mathrm{mg}, 80 \mathrm{mg}^{\mathrm{a}} \\
\text { paroxetine } 20 \mathrm{mg}\end{array}$ & $\begin{array}{l}\text { DLX 91 } \\
\text { SSRI } 89\end{array}$ \\
\hline HMAT B & $\begin{array}{l}\text { MDD } \\
\text { HAMD } \geq 15 \\
\text { CGI-S } \geq 4\end{array}$ & 8 & $\begin{array}{l}\mathrm{DLX} 40 \mathrm{mg}, 80 \mathrm{mg}^{\mathrm{a}} \\
\text { paroxetine } 20 \mathrm{mg}\end{array}$ & $\begin{array}{l}\text { DLX } 86^{\mathrm{b}} \\
\text { SSRI } 87\end{array}$ \\
\hline HMCR & $\begin{array}{l}\text { MDD } \\
\text { MADRS } \geq 22 \\
\text { CGI-S } \geq 4\end{array}$ & 8 & $\begin{array}{l}\text { DLX } 60 \mathrm{mg} \\
\text { escitalopram } 10 \mathrm{mg}\end{array}$ & $\begin{array}{l}\text { DLX } 273 \\
\text { SSRI } 274\end{array}$ \\
\hline HMCV & $\begin{array}{l}\text { MDD } \\
\text { HAMD } \geq 15 \\
\text { CGI-S } \geq 4\end{array}$ & 9 & $\begin{array}{l}\text { DLX } 60 \mathrm{mg} \\
\text { paroxetine } 20 \mathrm{mg}\end{array}$ & $\begin{array}{l}\text { DLX } 238 \\
\text { SSRI } 240\end{array}$ \\
\hline
\end{tabular}

Notes: a $80 \mathrm{mg}$ dose were excluded from the analysis; ' $\mathrm{DLX} 40 \mathrm{mg}$ arm.

Abbreviations: CGI-S, Clinical Global Impression-Severity; DLX, duloxetine; HAMD, Hamilton Rating Scale for Depression; MADRS, Montgomery-Åsberg Depression Rating Scale; MDD, major depressive disorder; n, number of patients; SSRI, selective serotonin reuptake inhibitor.

Common inclusion criteria for the included studies (HMAT A, HMAT B, HMCV, HMCR) were as follows: male or female outpatients aged at least 18 years who met DSM-IV (Diagnostic and Statistical Manual for Mental Disorders, 4th Edition) ${ }^{17}$ criteria for nonpsychotic MDD and had a Clinical Global Impression score $\geq 4$, a 17-item Hamilton Rating Scale for Depression $\left(\mathrm{HAMD}_{17}\right)$ total score $\geq 15$, or a Montgomery-Åsberg Depression Rating Scale score $\geq 22$.

The HMAT study (groups A and B) was a multicenter, parallel, double-blind, randomized, placebo-controlled and active comparator-controlled study with a blinded placebo lead-in and placebo lead-out. The primary objective was to assess mean changes in $\mathrm{HAMD}_{17}$ total score from baseline to endpoint (week 8). The treatments were duloxetine 40 or $80 \mathrm{mg} /$ day, paroxetine $20 \mathrm{mg} /$ day, or placebo.

The HMCV study was a multicenter, randomized, doubleblind, double-dummy, parallel, active treatment-controlled Phase III trial comparing the efficacy and safety of duloxetine $60 \mathrm{mg} /$ day and paroxetine $20 \mathrm{mg}$ /day for inpatients and outpatients with MDD. The study included 8 weeks of active treatment followed by a one-week dose-tapering period. The primary objective of the study was to determine whether duloxetine $60 \mathrm{mg}$ /day was noninferior to paroxetine $20 \mathrm{mg}$ / day in the acute treatment of patients with MDD, as assessed by the baseline-to-endpoint change in $\mathrm{HAMD}_{17}$ total score over an 8-week period. ${ }^{13}$

The HMCR study was a multicenter, randomized, 8-month, placebo-controlled, double-blind study that evaluated the comparative efficacy of duloxetine and escitalopram for patients with MDD. ${ }^{14,15}$ The primary objective was to compare the onset of antidepressant efficacy for patients 
taking duloxetine $60 \mathrm{mg} /$ day or escitalopram $10 \mathrm{mg} /$ day. This objective was evaluated by testing the hypothesis that the percentage of patients taking duloxetine who met onset criteria at week 2 was not inferior to (or at least as good as) the percentage of patients taking escitalopram.

\section{Statistical analysis}

Efficacy analyses included a comparison of duloxetine versus two SSRIs and placebo. The primary endpoint was mean change from baseline in $\mathrm{HAMD}_{17}$ total score at week 8. Secondary endpoints were mean change in $\mathrm{HAMD}_{17}$ subscale score, response rate, remission rate, and mean change in Hamilton Anxiety Rating Scale (HAMA) total score from baseline to week 8 . Response was defined as a $\geq 50 \%$ reduction in $\mathrm{HAMD}_{17}$ total score from baseline at week 8. Remission was defined by a $\mathrm{HAMD}_{17}$ total score $\leq 7$ at week 8 .

Our analyses included two groups: all randomized patients who had a $\mathrm{HAMD}_{17}$ total score $\geq 15$ and a subgroup of more severe patients who had a $\mathrm{HAMD}_{17}$ total score $\geq 19$. This division was included because some studies suggest that patients with severe symptoms may have different treatment needs. ${ }^{4,18}$

HAMD $_{17}$ items include (1) depressive mood; (2) feelings of guilt; (3) suicide; (4) early insomnia; (5) middle insomnia; (6) late insomnia; (7) work and activities; (8) psychomotor retardation; (9) agitation; (10) psychic anxiety; (11) somatic anxiety; (12) somatic symptoms gastrointestinal; (13) general somatic symptoms; (14) genital symptoms; (15) hypochondriasis; (16) weight loss; and (17) insight. ${ }^{19}$

Five $\mathrm{HAMD}_{17}$ subscales were used for the subgroup analysis: Bech (items 1, 2, 7, 8, 10, 13) and Maier (1, 2, 7, $8,9,10)$, comprising items generally considered to be the core symptoms of depression; Retardation (items 1, 7, 8, 14), evaluating the degree of energy and interest levels; Sleep (items 4, 5, 6) assessing the degree of insomnia; and Anxiety/ Somatization (items $10,11,12,13,15,17$ ) and HAMA total score, assessing anxiety. ${ }^{19-23}$

For the analysis of primary and secondary endpoints, missing data were imputed using the last observation carried forward approach. Continuous variables were calculated using analysis of covariance based on last observation carried forward values as follows: one analysis of covariance model was calculated for each study (counting the groups A and B of the HMAT study as two studies), with a fixed effect for investigator, treatment, and baseline score as covariates. Effect sizes in each model were calculated using least squares mean differences divided by the standard deviation of the residuals provided by the model of this study. Overall least squares mean estimates and effect sizes were calculated as a weighted mean of the corresponding estimates in all studies, with weights based on within-study variance, assuming a fixed study effect. The binary outcomes were analyzed using the Cochran-Mantel-Haenszel test adjusted for study. Relative risk is presented with $95 \%$ confidence intervals (CI) and $P$-values. The odds ratio (OR) was adjusted for the study by calculating the ORs within each study and then weighting these ORs across studies. Absolute numbers and averages were not adjusted for study and therefore cannot be directly compared with the ORs.

Safety and tolerability measures included patient-reported treatment-emergent adverse events and overall rates of study discontinuation due to adverse events. Reasons for discontinuation from the study were listed and treatment-emergent adverse events were reported using the Medical Dictionary for Regulatory Activities Terminology. Safety was analyzed by treatment descriptive statistics, and categorical safety measures were evaluated using Fisher's Exact test.

\section{Results}

\section{Patient demographics and disposition}

At baseline, patients were mostly middle-aged (mean age $40.8-42.0$ years), female (range $63.8 \%-67.4 \%$ ), with mean $\mathrm{HAMD}_{17}$ total scores ranging from 17.6 to 19.0 and mean HAMA total scores ranging from 14.4 to 15.8 . The majority of patients were Caucasian; patients from East Asia accounted for approximately $30 \%$ of duloxetine-treated and SSRI-treated patients (Table 2). Completion rates were approximately $70 \%$ (68.6\% for duloxetine-treated patients, $72.3 \%$ for SSRI-treated patients, and $66.8 \%$ for placebotreated patients). Adverse events were common reasons for discontinuation (duloxetine-treated patients, $8.9 \%$; SSRItreated patients, 7.1\%; placebo-treated patients, $6.0 \%$; see Table 3). Discontinuation due to lack of efficacy was more likely in placebo-treated patients than in duloxetine-treated or SSRI-treated patients $(13.3 \%$ versus $3.2 \%$ and $3.2 \%$, respectively).

\section{Efficacy comparison using $\mathrm{HAMD}_{17}$ and HAMA scores}

A comparison of the mean changes in $\mathrm{HAMD}_{17}$ total, subscale scores and HAMA total score from baseline at week 8 (last observation carried forward) is shown in Table 4; corresponding effect sizes are shown in Figure 1. In the total population, no statistically significant differences were found in the mean change in $\mathrm{HAMD}_{17}$ total score at week 8 between duloxetinetreated and SSRI-treated patients $(-10.08$ and -9.69 , 
Table 2 Patient demographics

\begin{tabular}{|c|c|c|c|c|}
\hline Characteristics & $\begin{array}{l}\text { Total } \\
(n=I, 694)\end{array}$ & $\begin{array}{l}\text { Duloxetine } \\
(n=688)\end{array}$ & $\begin{array}{l}\text { SSRI } \\
(n=690)\end{array}$ & $\begin{array}{l}\text { Placebo } \\
(n=3 \mid 6)\end{array}$ \\
\hline \multicolumn{5}{|l|}{ Age } \\
\hline Mean (SD) & $41.3(13.4)$ & $40.8(12.9)$ & $4 I .4(14.0)$ & $42.0(13.1)$ \\
\hline \multicolumn{5}{|l|}{ Gender, n (\%) } \\
\hline Female & $\mathrm{I}, \mathrm{I} 07(65.3)$ & $439(63.8)$ & $465(67.4)$ & $203(64.2)$ \\
\hline Male & $587(34.7)$ & $249(36.2)$ & $225(32.6)$ & $113(35.8)$ \\
\hline \multicolumn{5}{|l|}{ Race/ethnicity, n (\%) } \\
\hline Caucasian & $988(58.3)$ & $370(53.8)$ & $360(52.2)$ & $258(8 I .6)$ \\
\hline East Asian & $459(27.1)$ & $226(32.8)$ & $231(33.5)$ & $2(0.6)$ \\
\hline African descent & $130(7.7)$ & $50(7.3)$ & $46(6.7)$ & $34(10.8)$ \\
\hline Other & $117(6.9)$ & $42(6.1)$ & $53(7.7)$ & $22(7.0)$ \\
\hline \multicolumn{5}{|c|}{ Geographical region, n (\%) } \\
\hline USA & $\mathrm{I}, 216(7 \mathrm{I} .8)$ & $450(65.4)$ & $450(65.2)$ & $316(100)$ \\
\hline China & $244(14.4)$ & $12 \mid(17.6)$ & $123(17.8)$ & $0(0.0)$ \\
\hline Korea & $123(7.3)$ & 61 (8.9) & $62(9.0)$ & $0(0.0)$ \\
\hline Taiwan & $68(4.0)$ & $34(4.9)$ & $34(4.9)$ & $0(0.0)$ \\
\hline Brazil & $43(2.5)$ & $22(3.2)$ & $21(3.0)$ & $0(0.0)$ \\
\hline \multicolumn{5}{|c|}{ Number of previous episodes } \\
\hline Mean (SD) & $4.2(2 । .2)$ & $4.7(30.2)$ & $3.5(12.2)$ & $4.8(9.3)$ \\
\hline \multicolumn{5}{|c|}{ Duration of current episode (months) } \\
\hline Mean (SD) & $13.0(27.8)$ & $12.6(2 \mid .7)$ & $12.7(32.6)$ & $14.6(28.4)$ \\
\hline \multicolumn{5}{|c|}{ MADRS total score at baseline } \\
\hline Mean (SD) & $26.9(7.2)$ & $27.2(7.1)$ & $27.3(7.1)$ & $26.0(7.5)$ \\
\hline \multicolumn{5}{|c|}{ HAMA total score at baseline } \\
\hline Mean (SD) & $15.5(5.9)$ & $15.7(5.9)$ & $15.8(6.0)$ & $14.4(5.3)$ \\
\hline \multicolumn{5}{|c|}{ HAMD total score at baseline } \\
\hline Mean (SD) & $18.7(5.1)$ & $18.9(5.1)$ & $19.0(5.1)$ & $17.6(5.0)$ \\
\hline
\end{tabular}

Abbreviations: HAMA, Hamilton Rating Scale for Anxiety; HAMD, Hamilton Rating Scale for Depression; MADRS, Montgomery-Åsberg Depression Rating Scale; N, total number of patients; $n$, total number of affected patients; SD, standard deviation; SSRI, selective serotonin reuptake inhibitor.

respectively). However, the differences between duloxetine versus placebo and SSRI versus placebo were statistically significant $(P<0.01)$. Duloxetine and SSRI were comparable on most other efficacy measures; however, duloxetine-treated patients showed a greater mean change from baseline in HAMD $_{17}$ Retardation subscale score compared with SSRItreated patients (least squares mean difference $[95 \% \mathrm{CI}]$ )

Table 3 Reasons for discontinuation

\begin{tabular}{|c|c|c|c|}
\hline Parameter & $\begin{array}{l}\text { Duloxetine } \\
(\mathrm{N}=688)\end{array}$ & $\begin{array}{l}\text { SSRI } \\
(N=690)\end{array}$ & $\begin{array}{l}\text { Placebo } \\
(\mathrm{N}=3 \mid 6)\end{array}$ \\
\hline Patients completed, n (\%) & $472(68.6)$ & $499(72.3)$ & $211(66.8)$ \\
\hline Patients discontinued, n (\%) & $216(31.4)$ & $190(27.5)$ & $105(33.2)$ \\
\hline Adverse events & $61(8.9)$ & $49(7.1)$ & $19(6.0)$ \\
\hline Death & 0 & $\mathrm{I}(0.1)$ & 0 \\
\hline Lack of efficacy & $22(3.2)$ & $22(3.2)$ & $42(13.3)$ \\
\hline Lost to follow-up & $38(5.5)$ & $30(4.3)$ & $18(5.7)$ \\
\hline Physician decision & $\mathrm{I}(0.1)$ & $5(0.7)$ & $2(0.6)$ \\
\hline Protocol violation & $19(2.8)$ & $21(3.0)$ & $7(2.2)$ \\
\hline Sponsor decision & $\mathrm{I}(0.1)$ & $\mathrm{I}(0.1)$ & 0 \\
\hline Subject decision & $74(10.8)$ & $61(8.8)$ & $17(5.4)$ \\
\hline Unknown & 0 & $\mathrm{I}(0.1)$ & 0 \\
\hline
\end{tabular}

Abbreviations: $\mathrm{N}$, total number of patients; $\mathrm{n}$, number of affected patients; SSRI, selective serotonin reuptake inhibitor.
$(-0.33[-0.60,-0.07])$. For the more severe subgroup with $\mathrm{HAMD}_{17}$ total scores $\geq 19$ at baseline, again statistically significant differences were found in mean change in $\mathrm{HAMD}_{17}$ total scores at week 8, but greater efficacy for duloxetine was seen with the Bech, Maier, and Retardation subscale scores compared with SSRIs: HAMD ${ }_{17} \operatorname{Bech}(-0.62[-1.16,-0.08])$, HAMD $_{17}$ Maier $(-0.65[-1.18,-0.12])$, and HAMD ${ }_{17}$ Retardation $(-0.45[-0.83,-0.07])$.

In the total population, $\mathrm{HAMD}_{17}$ total score effect sizes for duloxetine and SSRI versus placebo were comparable ( 0.260 and 0.256 , respectively). Differences in some HAMD subscale scores indicated an advantage for duloxetine over SSRIs. These were seen on the Retardation subscales for the total population ( 0.337 versus 0.191 , respectively) in the more severe population ( 0.409 versus 0.154 , respectively), and on the Bech and Maier subscales for the more severe population (Figure 1).

\section{Response}

The response rates at week 8 were $42.0 \%$ for the duloxetine-treated patients, $44.5 \%(\mathrm{n}=307)$ for the SSRI-treated patients, and $24.4 \%(n=77)$ for the placebo-treated patients. 


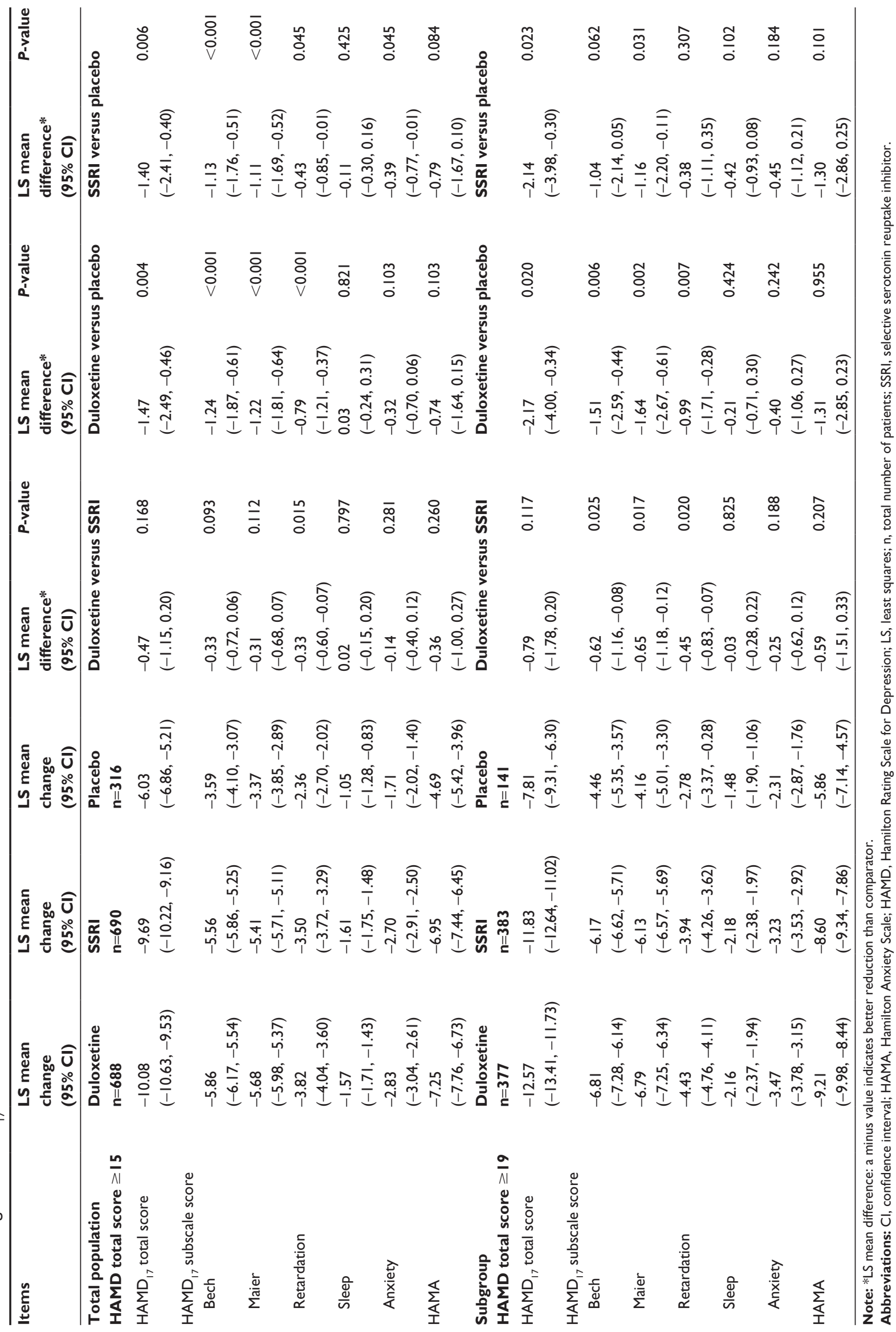



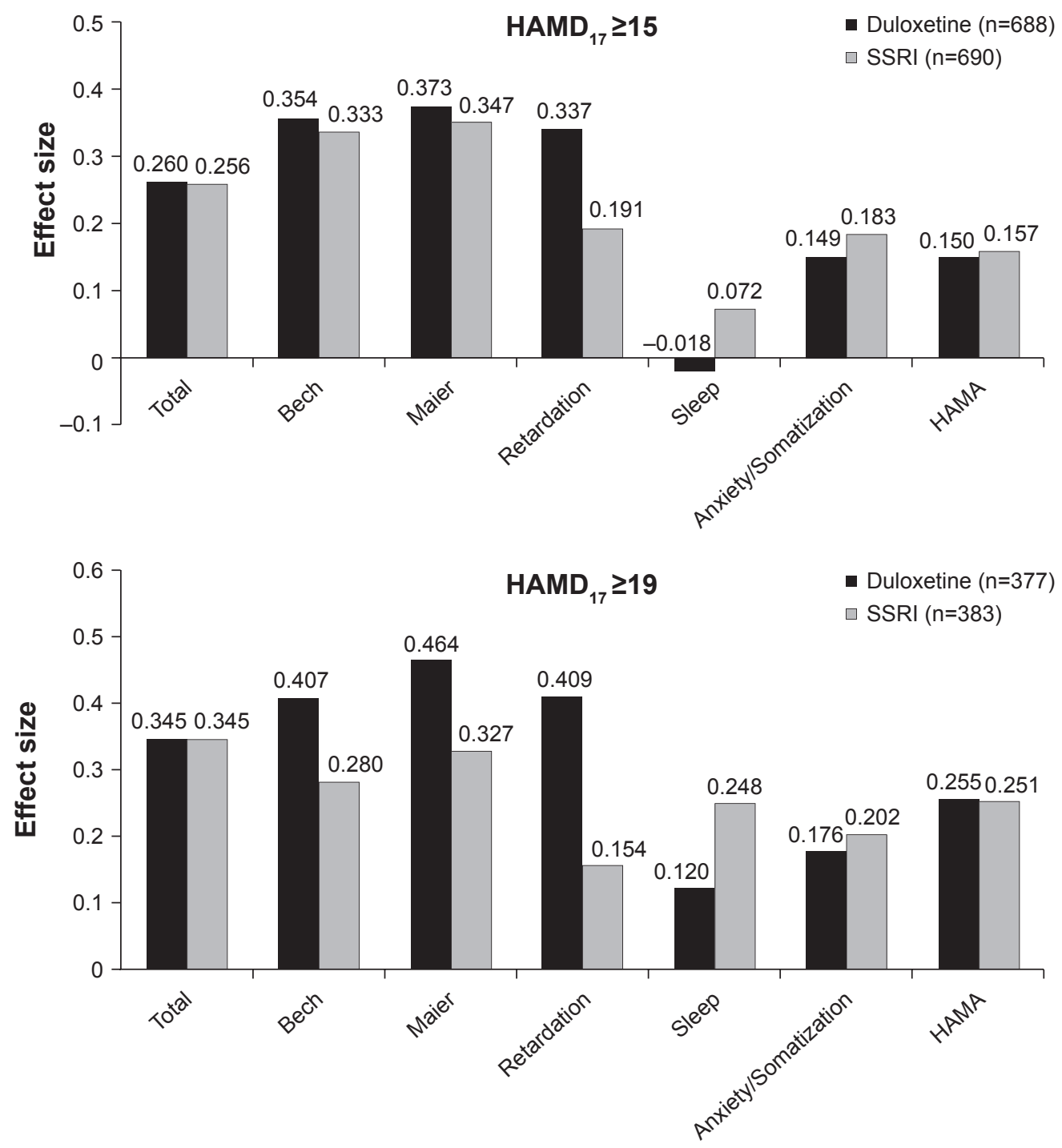

Figure I Effect sizes for duloxetine and SSRls versus placebo in mean changes on $\mathrm{HAMD}_{17}$ total score, HAMD 17 subscale score, and HAMA total score at week 8 . Total population $\left(\mathrm{HAMD}_{17} \geq 15\right)$ and more severe population $\left(\mathrm{HAMD}_{17} \geq 19\right)$.

Abbreviations: HAMA, Hamilton Anxiety Rating Scale; HAMD ${ }_{17}$, 17-item Hamilton Rating Scale for Depression; SSRIs, selective serotonin reuptake inhibitor.

No statistically significant difference was found between the duloxetine-treated and SSRI-treated patients (OR 1.05; 95\% CI 0.80-1.37). Statistically significant differences were shown for the duloxetine-treated versus placebo-treated patients (OR $1.61 ; 95 \%$ CI 1.11-2.33) and the SSRI-treated versus placebotreated patients (OR 1.83; 95\% CI 1.27-2.64).

\section{Remission}

The remission rates at week 8 were $35.2 \%$ for the duloxetinetreated patients, $36.1 \%(n=249)$ for the SSRI-treated patients, and $21.2 \%(\mathrm{n}=67)$ for the placebo-treated patients. No statistically significant differences were found at week 8 for the duloxetine-treated versus SSRI-treated patients (OR $1.11 ; 95 \%$ CI $0.64-1.92$ ), the duloxetine-treated versus placebo-treated patients (OR 1.53; 95\% CI 0.74-3.18), or the SSRI-treated versus placebo-treated patients (OR 1.60; 95\% CI 0.77-3.33).

\section{Safety}

The most common treatment-emergent adverse events are summarized in Table 5. Among duloxetine-treated patients, nausea (25.7\%), dry mouth (17.3\%), dizziness (12.6\%), constipation (11.0\%), and decreased appetite (11.9\%) had a higher incidence than in placebo-treated patients, but the rates of these adverse events were similar between duloxetine-treated and SSRI-treated patients except for nausea and dry mouth.

\section{Discussion}

Our results show that duloxetine and SSRI treatment within their respective approved dosage in Japan demonstrated 
Table 5 Adverse events with $>5 \%$ incidence

\begin{tabular}{llll}
\hline Parameter & $\begin{array}{l}\text { Duloxetine } \\
(\mathbf{n = 6 8 8})\end{array}$ & $\begin{array}{l}\text { SSRI } \\
(\mathbf{n}=690)\end{array}$ & $\begin{array}{l}\text { Placebo } \\
(\mathbf{n}=\mathbf{3} \text { I6) }\end{array}$ \\
\hline Patients with at least one TEAE & $569(82.7)$ & $533(77.2)$ & $234(74.1)$ \\
Nausea & $177(25.7)$ & $115(16.7)$ & $19(6.0)$ \\
Headache & $113(16.4)$ & $117(17.0)$ & $52(16.5)$ \\
Dry mouth & $119(17.3)$ & $77(11.2)$ & $21(6.6)$ \\
Dizziness & $87(12.6)$ & $81(11.7)$ & $18(5.7)$ \\
Constipation & $76(11.0)$ & $62(9.0)$ & $17(5.4)$ \\
Decreased appetite & $82(11.9)$ & $55(8.0)$ & $7(2.2)$ \\
Diarrhea & $46(6.7)$ & $66(9.6)$ & $26(8.2)$ \\
Somnolence & $57(8.3)$ & $56(8.1)$ & $10(3.2)$ \\
Insomnia & $54(7.8)$ & $39(5.7)$ & $17(5.4)$ \\
Fatigue & $38(5.5)$ & $42(6.1)$ & $17(5.4)$ \\
\hline
\end{tabular}

Abbreviations: $n$, total number of patients; SSRI, selective serotonin reuptake inhibitors; TEAE, treatment-emergent adverse event.

comparable efficacy with regard to overall depressive symptoms. However, certain $\mathrm{HAMD}_{17}$ subscale scores responded differently to duloxetine compared with SSRIs, and this may clarify the difference in clinical attributes among these antidepressants.

First, when assessing overall efficacy using the mean changes in $\mathrm{HAMD}_{17}$ total scores from baseline, both duloxetine and SSRI demonstrated greater efficacy than placebo, but did not indicate any significant difference between each other for either the total population $\left(\mathrm{HAMD}_{17}\right.$ total score $\geq 15$ ) or the more severe population $\left(\mathrm{HAMD}_{17}\right.$ total score $\geq 19$ ). On the one hand, this is consistent with a prior report by Thase et al, ${ }^{4}$ where all randomized patients across any severity were analyzed and no significant difference in efficacy between duloxetine and SSRI was found. However, on the other hand, this is inconsistent with prior reports that duloxetine $\leq 120 \mathrm{mg}$ /day showed greater efficacy than SSRIs in patients with at least moderately severe depression., ${ }^{4} 16$ Given this and the finding of a modest dose response trend for duloxetine efficacy by Mallinckrodt et $\mathrm{al}^{16}$ this inconsistency may be explained by the upper limit on the dosage of duloxetine ( $\leq 60 \mathrm{mg} /$ day) in this study.

Second, when assessing energy and interest using Retardation subscale scores, duloxetine showed greater efficacy regardless of baseline depression severity $\left(\mathrm{HAMD}_{17}\right.$ total score $\geq 15$ or $\geq 19$ ). This is consistent with previous reports by Mallinckrodt et a $1^{16}$ and Martinez et al. ${ }^{24}$ Furthermore, Katz et $\mathrm{al}^{25}$ reported that desipramine (a norepinephrine reuptake inhibitor) demonstrated better efficacy than paroxetine (an SSRI) on psychomotor retardation symptoms. These results may be explained by the effect of duloxetine on norepinephrine, which has been shown to be associated with arousal and activity. ${ }^{26}$
The current results show some inconsistency with a report by Cipriani et al in which some SSRIs were significantly more efficacious than duloxetine. This is partly due to the different methodologies used in that study and in our current study. In Cipriani et al, ${ }^{12}$ approximately one third of the comparisons were direct comparisons from randomized controlled trials and many of the pairwise comparisons were based on only one study. Furthermore, a "moderate" degree of heterogeneity and statistical incoherence (estimates based on the direct comparisons are not contained in the $95 \% \mathrm{CI}$ for indirect comparisons) in the study network were detected. Study conclusions based on direct comparisons were much more conservative than those based on indirect ones. On the other hand, the strengths of this database analysis are that it analyzed individual patient data, used the same analysis method and endpoint across studies, and included similar patients. The adopted database analysis design allowed for a homogeneous patient population, with almost the same inclusion criteria and the exact same endpoint. Although our analysis resulted in a comparatively smaller number of studies and patients, it achieved high internal validity and reproducibility. In addition, direct comparisons of head-to-head data enabled us to avoid the uncertainty of how much the two different evidence levels are weighted when pooling direct and indirect comparisons.

\section{Limitations}

Several limitations of the current report warrant discussion. The integrated database only included studies that were conducted by Eli Lilly or its partners outside Japan; therefore, sponsorship bias cannot be fully mitigated. Using this database resulted in inclusion of fewer studies than publication-based meta-analyses; however, this methodology enabled us to analyze individual patient data that are not available in many publications. Similarly, using this global database resulted in inclusion of Caucasians as the majority $(58.3 \%)$ of the patient population. Another limitation of this meta-analysis is that it only consisted of two SSRIs (paroxetine and escitalopram) although four SSRIs are available in Japan. Furthermore, SSRI doses used in this analysis (paroxetine $20 \mathrm{mg}$ /day and escitalopram $10 \mathrm{mg} /$ day) were at the lower approved dosage in Japan (20-40 mg/day for paroxetine, and 10-20 mg/day for escitalopram), whereas the duloxetine doses used in this analysis $(40 \mathrm{mg} /$ day or $60 \mathrm{mg} /$ day) were the dosages approved in Japan. Further research that includes all available SSRIs using flexible dosing within their full therapeutic ranges will make it possible to generalize conclusions to the SSRI group as a whole. In addition, the exclusion of patients randomized 
to duloxetine $>60 \mathrm{mg} /$ day limits the ability to generalize conclusions in some countries with approved dosages above a maximum of $60 \mathrm{mg} / \mathrm{day}$, but this was not within the scope of our analysis. Lastly, in these analyses, no correction for multiplicity was performed, so superiority based on $P$-values cannot be assessed.

\section{Conclusion}

Comparison between duloxetine and SSRI demonstrated comparable efficacy within the Japan-approved dose range in patients with MDD. Results of the HAMD ${ }_{17}$ subscale analysis indicated that duloxetine might be superior to SSRIs in improving loss of energy and interest.

\section{Author contributions}

$\mathrm{EH}, \mathrm{AS}$, and LM conceived and designed the study. AS conducted the data analysis and all authors were involved in interpretation of data. All authors critically revised the manuscript for important intellectual content and approved the final version.

\section{Disclosure}

This study was funded by Eli Lilly and Company and Shionogi \& Co Ltd. EH, AS, LM, and RE are employees and stockholders in Eli Lilly and Company. TK has received honoraria from Astellas, Eli Lilly Japan, Meiji Seika, Mitsubishi Tanabe, MSD, Otsuka, and Pfizer, and has received research grants from Astellas, Dainippon Sumitomo, GlaxoSmithKline, and Pfizer. TK is also an advisory board member for GlaxoSmithKline, and has served as a consultant for Asahi-kasei. TT is a full-time employee and stockholder in Shionogi \& Co Ltd. A part of this paper was presented at The International College of Neuropsychopharmacology Special Congress on Addiction and Mental Health 2013 (Kuala Lumpur City, Malaysia, October 1-4, 2013). Editorial assistance was provided by Angela Lorio and writing assistance was provided by Jody Arsenault, InVentiv Health Clinical, with financial support from Eli Lilly and Company. The authors report no other conflicts of interest in this work.

\section{References}

1. Treuer T, Liu CY, Salazar G, et al. Use of antidepressants in the treatment of depression in Asia: guidelines, clinical evidence, and experience revisited. Asia Pac Psychiatry. 2013;5(4):219-230.

2. Japanese Society of Mood Disorders. [Treatment Guideline II: Major Depressive Disorder, 2012 Ver. 1]. Japanese Society of Mood Disorders. July 26, 2012. Japanese.

3. Papakostas GI, Thase ME, Fava M, Nelson JC, Shelton RC. Are antidepressant drugs that combine serotonergic and noradrenergic mechanisms of action more effective than the selective serotonin reuptake inhibitors in treating major depressive disorder? A meta-analysis of studies of newer agents. Biol Psychiatry. 2007;62(11):1217-1227.
4. Thase ME, Pritchett YL, Ossanna MJ, Swindle RW, Xu J, Detke MJ. Efficacy of duloxetine and selective serotonin reuptake inhibitors: comparisons as assessed by remission rates in patients with major depressive disorder. J Clin Psychopharmacol. 2007;27(6):672-676.

5. Thase ME. Overview of antidepressant therapy. Manag Care. 2001; 10(8 Suppl):6-9.

6. Hansen RA, Gartlehner G, Lohr KN, Gaynes BN, Carey TS. Efficacy and safety of second-generation antidepressants in the treatment of major depressive disorder. Ann Intern Med. 2005;143(6):415-426.

7. Gartlehner G, Gaynes BN, Hansen RA, et al. Comparative benefits and harms of second-generation antidepressants: background paper for the American College of Physicians. Ann Intern Med. 2008;149(10): 734-750.

8. Gartlehner G, Thaler K, Hansen RA, Gaynes BN. The general and comparative efficacy and safety of duloxetine in major depressive disorder: a systematic review and meta-analysis. Drug Saf. 2009;32(12): 1159-1173.

9. Smith D, Dempster C, Glanville J, Freemantle N, Anderson I. Efficacy and tolerability of venlafaxine compared with selective serotonin reuptake inhibitors and other antidepressants: a meta-analysis. $\mathrm{Br} J$ Psychiatry. 2002;180:396-404.

10. National Institute for Clinical Excellence. Clinical practice guideline No 23. Depression: management of depression in primary and secondary care. London, UK: National Institute for Clinical Excellence; 2004. Available from: http://www.nice.org.uk/guidance/cg23. Accessed November 19, 2014.

11. Gartlehner G, Hansen RA, Morgan LC, et al. Comparative benefits and harms of second-generation antidepressants for treating major depressive disorder: an updated meta-analysis. Ann Intern Med. 2011;155(11): 772-785.

12. Cipriani A, Furukawa TA, Salanti G, et al. Comparative efficacy and acceptability of 12 new-generation antidepressants: a multipletreatments meta-analysis. Lancet. 2009;373(9665):746-758.

13. Lee $\mathrm{P}, \mathrm{Shu} \mathrm{L}, \mathrm{Xu} X$, et al. Once-daily duloxetine $60 \mathrm{mg}$ in the treatment of major depressive disorder: multicenter, double-blind, randomized, paroxetine-controlled, non-inferiority trial in China, Korea, Taiwan and Brazil. Psychiatry Clin Neurosci. 2007;61(3):295-307.

14. Pigott TA, Prakash A, Arnold LM, Aaronson ST, Mallinckrodt CH, Wohlreich MM. Duloxetine versus escitalopram and placebo: an 8-month, double-blind trial in patients with major depressive disorder. Curr Med Res Opin. 2007;23(6):1303-1318.

15. Nierenberg AA, Greist JH, Mallinckrodt CH, et al. Duloxetine versus escitalopram and placebo in the treatment of patients with major depressive disorder: onset of antidepressant action, a non-inferiority study. Curr Med Res Opin. 2007;23(3):401-416.

16. Mallinckrodt CH, Prakash A, Houston JP, Swindle R, Detke MJ, Fava M. Differential antidepressant symptom efficacy: placebo-controlled comparisons of duloxetine and SSRIs (fluoxetine, paroxetine, escitalopram). Neuropsychobiology. 2007;56(2-3):73-85.

17. American Psychiatric Association. Diagnostic and Statistical Manual of Mental Disorders Text Revision (DSM-IV-TR). 4th ed. Washington, DC, USA: American Psychiatric Association, 2000.

18. Thase ME, Simons AD, Cahalane J, McGeary J, Harden T. Severity of depression and response to cognitive behavior therapy. Am J Psychiatry. 1991;148(6):784-789.

19. Hamilton M. A rating scale for depression. J Neurol Neurosurg Psychiatry. 1960;23(1):56-62.

20. Hamilton M. The assessment of anxiety states by rating. $\mathrm{Br} J$ Med Psychol. 1959;32(1):50-55.

21. Maier W, Philipp M. Improving the assessment of severity of depressive states: a reduction of the Hamilton Depression Scale. Pharmacopsychiatry. 1985;18(1):114-115.

22. Cleary P, Guy W. Factor analysis of the Hamilton Depression Scale. Drugs Exp Clin Res. 1977;1(1-2):115-120.

23. Bech P, Gram LF, Dein E, Jacobsen O, Vitger J, Bolwig TG. Quantitative rating of depressive states. Acta Psychiatr Scand. 1975;51(3): $161-170$. 
24. Martinez JM, Katon W, Greist JH, et al. A pragmatic 12-week, randomized trial of duloxetine versus generic selective serotonin-reuptake inhibitors in the treatment of adult outpatients in a moderate-to-severe depressive episode. Int Clin Psychopharmacol. 2012;27(1):17-26.

25. Katz MM, Tekell JL, Bowden CL, et al. Onset and early behavioral effects of pharmacologically different antidepressants and placebo in depression. Neuropsychopharmacology. 2004;29(3):566-579.
26. Morilak DA, Frazer A. Antidepressants and brain monoaminergic systems: a dimensional approach to understanding their behavioral effects in depression and anxiety disorders. Int $J$ Neuropsychopharmacol. 2004;7(2):193-218.

\section{Publish your work in this journal}

Neuropsychiatric Disease and Treatment is an international, peerreviewed journal of clinical therapeutics and pharmacology focusing on concise rapid reporting of clinical or pre-clinical studies on a range of neuropsychiatric and neurological disorders. This journal is indexed on PubMed Central, the 'PsycINFO' database and CAS, and is the official journal of The International Neuropsychiatric Association (INA). The manuscript management system is completely online and includes a very quick and fair peer-review system, which is all easy to use. Visit http://www.dovepress.com/testimonials.php to read real quotes from published authors.

Submit your manuscript here: http://www.dovepress.com/neuropsychiatric-disease-and-treatment-journal 